\title{
Ten Year Autopsy Study of Differentiating Features Between Hanging and Strangulation
}

\author{
Manoj Kumar Sharma ${ }^{1}$, Jaspinder Pratap Singh ${ }^{1}$, Kuldip Kumar ${ }^{2}$, Ashok Chanana ${ }^{3}$ \\ Junior Resident ${ }^{1}$, Associate Professor ${ }^{2}$, Professor and Head ${ }^{3}$, \\ Department of Forensic Medicine and Toxicology, Government Medical College, Amritsar
}

\begin{abstract}
Introduction: Hanging is that form of asphyxia which is caused by the suspension of the body by a ligature which encircles the neck, the constricting force being the weight of the body, or part of body weight. Strangulation is a form of death caused by constricting the neck by some means other than body weight. The means used may be ligature (ligature strangulation), human hand (throttling or manual strangulation), elbow (mugging), or some hard subject such as stick (bansdola).
\end{abstract}

\begin{abstract}
Aims and Objectives: To study the differentiating aspect between Hanging and Strangulation, with respect to type of ligature material and its position, external and internal finding of neck and changes in the subcutaneous tissue of neck.
\end{abstract}

Results: Hanging amounted for $50.37 \%$ cases while strangulation was $17.20 \%$ cases among the violent asphyxial deaths. Clothes (65.45\%) were most common ligature material both in hanging and strangulation as well. Position of ligature was above the level of thyroid in $95.12 \%$ cases while in strangulation the position of ligature was at level of thyroid in most of the cases (45.71\%). Associated injuries are present in $51.43 \%$ cases of strangulation. Subcutaneous tissue is white glistening in most of hanging cases $(76.58 \%)$ while contused in most of strangulation $(82.86 \%)$ cases.

Conclusion and Suggestions: It is suggested that in the interest of justice to avoid confusion, in all cases of violent asphyxial deaths, the post-mortem examination should be conducted by the Forensic experts only. Police personals should also be given training that they should not cut the ligature material and remove ligature material before post-mortem examination so that easy differentiation of hanging and strangulation can be made.

Keywords: Hanging, Strangulation, ligature material,violent asphyxial deaths, internal neck findings.

\section{Introduction}

Hanging is that form of asphyxia which is caused by the suspension of the body by a ligature which encircles the neck, the constricting force being the weight of the body, or part of body weight.

\footnotetext{
Corresponding Author: Jaspinder Pratap Singh Junior Resident, Department of Forensic Medicine and Toxicology, Government Medical College, Amritsar e-mail: jaspinderpsingh@gmail.com

Contact No.: 07888915385
}

\section{Hanging is classified on the basis of:}

(A) Degree of suspension, 1. Complete hanging: The body is completely suspended without any part of the body touching the ground. 2. Partial hanging: The body is partially suspended, the toes or feet touching the ground, or in sitting, kneeling, lying down, prone, or any posture with only head and chest off the ground.

(B) Position of the knot 1. Typical hanging: Knot is present over the central part over the back of the neck. 2. Atypical hanging: The knot is anywhere other than on the occiput, i.e., on the right or left side or front of the neck. ${ }^{1}$ 
The "mark of hanging" on the victim depends upon various factors like height of suspension point, nature and composition of the ligature material used, the weight of the body, duration of the suspension, things which intervene between the ligature material and skin of the neck. It requires an expert's skill and care for the determination of cause and manner of death. Multiple rounds of ligature around the neck with two or more fixed knots calls special care in interpretation to decide the cause and manner of death, other injuries over the neck and bodily injuries could complicate the matter. ${ }^{2}$

The level at which the ligature mark lies is also of importance in making the distinction between hanging and strangulation by a ligature. Strangulation is a form of death caused by constricting the neck by some means other than body weight. The cause of death in hanging and strangulation is mainly due to asphyxia. Still, it may be due to venous congestion, cerebral ischemia, shock, or a combination of more than two causes. Fracturedislocation of cervical vertebrae occurs in judicial hanging. Postmortem appearances vary according to mode of death. There are external and internal appearances. External appearances are due to ligature on the neck and those peculiar to the mode of death. The ligature mark on the neck varies according to the nature of the material used as a ligature, which requires a detail inspection. In complete hanging, the ligature mark is usually situated above thyroid cartilage between larynx and chin. It is directed obliquely upward along the line of the mandible (lower jaw) and reaches the mastoid process behind the ear. It is sometimes absent at the back where two limbs of noose stretch upward toward the knot. The mark may be found on or below the thyroid cartilage, especially in case of partial suspension. It may also be circular. In the case of strangulation by ligature, the mark is well defined and usually situated low down in the neck below the thyroid cartilages and encircling the neck horizontally and completely. The marks are multiple if ligature is twisted several times around the neck. It may be oblique as in hanging if the victim has been dragged by ligature or strangled in recumbent position. ${ }^{3}$

Aims and Objectives: The present study was carried out with a view to study the incidence and to study the differentiating aspect between Hanging and Strangulation, with respect to type of ligature material and its position, external and internal finding of neck and changes in the subcutaneous tissue of neck.

\section{Material and Method}

Data has been collected from autopsies conducted on dead bodies of cases of violent asphyxial deaths at the mortuary of department of Forensic Medicine and Toxicology, Govt. Medical College, Amritsar, during period of last 10 years from 1st. January 2006 to 31 st. December 2015.

407 cases of violent asphyxial deaths has been studied using pre-tested structured schedule, all cases of violent asphyxial deaths brought to department of Forensic Medicine and Toxicology, Government Medical College, Amritsar, mortuary for autopsy and those who fulfill the inclusion and exclusion criteria had been selected on a purposive sampling basis.

Inclusion Criteria: Autopsy on all cases of violent asphyxial deaths conducted at mortuary of department of Forensic Medicine and Toxicology, Govt. Medical College, Amritsar during a period of ten years.

\section{Exclusion Criteria:}

1. All deaths due to violence other than asphyxial death.

2. Deaths due to chemical asphyxiants.

3. Deaths due to poisoning.

4. Sudden natural deaths.

5 Deaths due to cold, starvation, heat and anaphylaxis.

\section{Observations:}

Table 1: Incidence of violent asphyxial deaths based on method of asphyxiation

\begin{tabular}{|l|c|c|}
\hline Type of Asphyxial death & No. of cases & $\mathbf{\%}$ \\
\hline Hanging & 205 & 50.37 \\
\hline Strangulation & 70 & 17.20 \\
\hline Throttling & 5 & 1.23 \\
\hline Traumatic asphyxia & 3 & 0.74 \\
\hline Suffocation & 4 & 0.98 \\
\hline Drowning & 120 & 29.48 \\
\hline Total & $\mathbf{4 0 7}$ & $\mathbf{1 0 0 . 0}$ \\
\hline
\end{tabular}


Table 2: Type of ligature material used in hanging and strangulation

\begin{tabular}{|c|c|c|c|c|c|c|c|c|c|c|}
\hline \multirow{3}{*}{ Ligature Material } & \multicolumn{4}{|c|}{ Hanging } & \multicolumn{4}{|c|}{ Strangulation } & \multicolumn{2}{|c|}{ Total } \\
\hline & \multicolumn{2}{|c|}{ Male } & \multicolumn{2}{|c|}{ Female } & \multicolumn{2}{|c|}{ Male } & \multicolumn{2}{|c|}{ Female } & \multirow{2}{*}{ No. } & \multirow{2}{*}{$\%$} \\
\hline & No. & $\%$ & No. & $\%$ & No. & $\%$ & No. & $\%$ & & \\
\hline Wire & 3 & 1.46 & 0 & 0.00 & 0 & 0.00 & 0 & 0.00 & 3 & 1.09 \\
\hline Rope & 49 & 23.90 & 20 & 9.76 & 10 & 14.29 & 10 & 14.29 & 89 & 32.36 \\
\hline String & 1 & 0.49 & 0 & 0.00 & 1 & 1.42 & 1 & 1.42 & 3 & 1.09 \\
\hline Clothes & 86 & 41.95 & 46 & 22.44 & 18 & 25.71 & 30 & 42.86 & 180 & 65.45 \\
\hline Total & 139 & 67.80 & 66 & 32.20 & 29 & 41.43 & 41 & $\mathbf{5 8 . 5 7}$ & 275 & 100.00 \\
\hline
\end{tabular}

Table 3: Position of ligature mark in hanging and strangulation

\begin{tabular}{|l|c|c|c|c|c|c|}
\hline \multirow{2}{*}{ Position of ligature mark } & \multicolumn{2}{|c|}{ Hanging } & \multicolumn{2}{c|}{ Strangulation } & \multicolumn{2}{c|}{ Total } \\
\cline { 2 - 7 } & No. & $\mathbf{\%}$ & No. & No & No. & 206 \\
\hline Above the thyroid cartilage & 195 & 95.12 & 11 & 15.71 & 34.91 \\
\hline Below the thyroid cartilage & 1 & 0.49 & 27 & 38.57 & 28 & 10.18 \\
\hline At the level of thyroid cartilage & 9 & 4.39 & 32 & 45.71 & 41 & 14.91 \\
\hline Total & $\mathbf{2 0 5}$ & $\mathbf{1 0 0 . 0 0}$ & $\mathbf{7 0}$ & $\mathbf{1 0 0 . 0 0}$ & $\mathbf{2 7 5}$ & $\mathbf{1 0 0 . 0 0}$ \\
\hline
\end{tabular}

Table 4: External findings of neck in case of hanging and strangulation

\begin{tabular}{|c|c|c|c|c|c|c|c|}
\hline \multirow{2}{*}{\multicolumn{2}{|c|}{ Details of ligature mark }} & \multicolumn{2}{|c|}{ Hanging } & \multicolumn{2}{|c|}{ Strangulation } & \multicolumn{2}{|c|}{ Total $(n=275)$} \\
\hline & & \multirow{2}{*}{$\begin{array}{l}\text { No. } \\
204\end{array}$} & \multirow{2}{*}{$\begin{array}{c}\mathbf{\%} \\
99.51\end{array}$} & \multirow{2}{*}{$\frac{\text { No. }}{65}$} & \multirow{2}{*}{$\begin{array}{c}\text { \% } \\
92.86\end{array}$} & \multirow{2}{*}{$\begin{array}{l}\text { No. } \\
269\end{array}$} & \multirow{2}{*}{$\begin{array}{c}\mathbf{\%} \\
97.82\end{array}$} \\
\hline & Single & & & & & & \\
\hline & Multiple & 1 & 0.49 & 5 & 7.14 & 6 & 2.18 \\
\hline \multirow{2}{*}{ Direction } & Oblique & 202 & 98.54 & 9 & 12.86 & 211 & 76.73 \\
\hline & Horizontal & 3 & 1.46 & 61 & 87.14 & 64 & 23.27 \\
\hline \multirow{2}{*}{ Ligature mark } & Complete & 1 & 0.49 & 19 & 27.14 & 20 & 7.27 \\
\hline & Partial & 204 & 99.51 & 51 & 72.86 & 255 & 92.73 \\
\hline \multirow{2}{*}{ Associated injuries } & Present & 19 & 9.27 & 34 & 48.57 & 53 & 19.27 \\
\hline & Absent & 186 & 90.73 & 36 & 51.43 & 222 & 80.73 \\
\hline \multirow{2}{*}{ Ecchymosis at edges } & Present & 78 & 38.05 & 38 & 54.29 & 116 & 42.18 \\
\hline & Absent & 127 & 61.95 & 32 & 45.71 & 159 & 57.82 \\
\hline \multirow{2}{*}{ Foreign body/material } & Present & 11 & 5.37 & 5 & 7.14 & 16 & 5.82 \\
\hline & Absent & 194 & 94.63 & 65 & 92.86 & 259 & 94.18 \\
\hline
\end{tabular}

Table 5: Internal findings of neck in case of hanging and strangulation

\begin{tabular}{|l|c|c|c|c|c|c|c|c|c|c|}
\hline \multirow{2}{*}{ Findings in neck } & \multicolumn{4}{|c|}{ Hanging } & \multicolumn{4}{c|}{ Strangulation } & \multicolumn{2}{c|}{ Total } \\
\cline { 2 - 12 } & \multicolumn{2}{|c|}{ Absent } & \multicolumn{2}{|c|}{ Present } & \multicolumn{2}{|c|}{ Absent } & \multicolumn{2}{c|}{ Present } & \multirow{2}{*}{ No. } & $\%$ \\
\cline { 2 - 12 } & No. & $\%$ & No. & $\%$ & No. & $\%$ & No. & $\%$ & & \\
\hline Fracture of thyroid cartilage & 203 & 99.02 & 2 & 0.98 & 62 & 88.57 & 8 & 11.43 & 275 & 100.00 \\
\hline Fracture of cricoid cartilage & 205 & 100.00 & 0 & 0.00 & 70 & 100.00 & 0 & 0.00 & 275 & 100.00 \\
\hline Fracture of hyoid bone & 200 & 97.56 & 5 & 2.44 & 63 & 90.00 & 7 & 10.00 & 275 & 100.00 \\
\hline Fracture of cervical vertebra & 205 & 100.00 & 0 & 0.00 & 70 & 100.00 & 0 & 0.00 & 275 & 100.00 \\
\hline
\end{tabular}




\begin{tabular}{|c|c|c|c|c|c|c|c|c|c|c|}
\hline \multirow{3}{*}{ Findings in neck } & \multicolumn{4}{|c|}{ Hanging } & \multicolumn{4}{|c|}{ Strangulation } & \multicolumn{2}{|c|}{ Total } \\
\hline & \multicolumn{2}{|c|}{ Absent } & \multicolumn{2}{|c|}{ Present } & \multicolumn{2}{|c|}{ Absent } & \multicolumn{2}{|c|}{ Present } & \multirow{2}{*}{ No. } & \multirow{2}{*}{$\%$} \\
\hline & No. & $\%$ & No. & $\%$ & No. & $\%$ & No. & $\%$ & & \\
\hline Tear of intima of carotid artery & 98 & 47.80 & 107 & 52.20 & 28 & 40.00 & 42 & 60.00 & 275 & 100.00 \\
\hline Tear of neck muscles & 18 & 8.78 & 187 & 91.22 & 4 & 5.71 & 66 & 94.29 & 275 & 100.00 \\
\hline Infiltration in the soft tissue & 1 & 0.49 & 204 & 99.51 & 0 & 0.00 & 70 & 100.00 & 275 & 100.00 \\
\hline
\end{tabular}

Table 6: Changes in subcutaneous tissue of neck in hanging and strangulation

\begin{tabular}{|l|c|c|c|c|c|c|c|}
\hline \multirow{2}{*}{ Type of asphyxial death } & \multicolumn{2}{|c|}{ White glistening } & \multicolumn{2}{c|}{ Contused } & \multicolumn{2}{c|}{ Normal } & \multirow{2}{*}{ Total } \\
\cline { 2 - 8 } & No. & $\mathbf{\%}$ & No. & \% & No. & \% & No. \\
\hline Hanging & 157 & 76.58 & 46 & 22.44 & 2 & 0.98 & 205 \\
\hline Strangulation & 12 & 17.14 & 58 & 82.86 & 0 & 0.00 & 70 \\
\hline
\end{tabular}

\section{Discussion}

In the total number of cases of hanging and strangulation, the offending weapons were found to be various types of ligature materials $37.82 \%$ of the males and $27.63 \%$ of females preferred soft materials (saree, veil, towel, etc.) whereas $23.27 \%$ of men and $11.27 \%$ women used hard ligature material (wire, rope, string, etc.). These findings correlate with the study of Patel et $\mathrm{al}^{4}$ where they found in hanging $80 \%$ of the victims used soft materials and $20 \%$ victims used hard materials. In strangulation cases, they found that $66.67 \%$ victims were strangulated by using soft material and $33.33 \%$ victims were strangulated by using hard materials. In a study conducted only on type of ligature material used for hanging by Sharma et $\mathrm{al}^{5}$ they found that soft material was used in $56.36 \%$ and hard material in $43.64 \%$ cases. In another study conducted only on type of ligature material used for hanging by Naik et $\mathrm{al}^{6}$ they found that soft material was used in $53.97 \%$ and hard material in $46.03 \%$. Lastly, in a study by Vijaynath et $\mathrm{al}^{7}$ on type of ligature material used for hanging, they found that soft material was used in $70 \%$ cases and hard material was used in $30 \%$.

In $97.82 \%$ cases of hanging and strangulation, the ligature mark was single in number while only in $2.18 \%$ cases it was multiple. In only $7.14 \%$ cases of strangulation, the ligature mark was multiple in number.

In $95.12 \%$ cases of hanging the ligature mark was situated above the level of thyroid cartilage followed by $4.39 \%$ of the cases showing the ligature mark below the level of thyroid cartilage, the least was a single case $(0.49 \%)$ showing the ligature mark at the level of thyroid cartilage. In hanging, the ligature mark is usually situated above the level of thyroid cartilage due to the fact that during the suspension of the body there is slippage of ligature material over the upper part of the neck and the constriction force being the weight of the body. While in strangulation in $15.71 \%$ cases the ligature mark was situated above the level of thyroid cartilage in $45.71 \%$ of the cases showing the mark below the level of thyroid cartilage and in $38.57 \%$ cases showing the ligature mark at the level of thyroid cartilage which is reverse trend as compared to hanging.

In $98.54 \%$ of the cases of hanging the ligature mark was obliquely placed over the front of neck and in only $0.49 \%$ of the cases it was horizontal. While this trend was reverse in strangulation in which in $87.14 \%$ of the cases the ligature mark was horizontally placed over the front of neck and in $12.86 \%$ of the cases it was oblique.

In $99.51 \%$ cases of hanging the ligature mark was partial and in only $0.49 \%$ of the cases showing the complete ligature mark. While in strangulation in $72.86 \%$ cases it was partial and in $27.14 \%$ cases the ligature mark was complete. These results correlate with the study by Patel et $\mathrm{al}^{4}$ who observed the following, among the hanging cases $100 \%$ victims had oblique ligature mark on the neck and $100 \%$ transverse ligature mark on the neck in strangulations. In $93.75 \%$ cases the ligature mark was above the level of thyroid cartilage while in $6.25 \%$ cases the ligature mark was at the level of thyroid cartilage in hanging deaths. 
The classical external asphyxial findings such as cyanosis in hanging was found in $97.07 \%$ cases, dribbling of saliva in $28.29 \%$ cases, protrusion of tongue in $31.71 \%$ of cases and it was clenched between teeth in $19.02 \%$ cases, seminal fluid discharge in $12.20 \%$ cases, external injury marks in $10.24 \%$ cases, froth from nostrils in $16.09 \%$ cases and rigor mortis in $96.10 \%$ cases. These results closely correlate with study made by Patel et $\mathrm{al}^{4}$ who observed the following: congestion of face $77.5 \%$, dribbling of saliva $71.25 \%$, discharge of semen $17.5 \%$, discharge of feces $13.75 \%$, struggle marks nil cases.

Internal findings in cases of hanging were found as, torn intima of common carotid artery in $52.20 \%$ cases, fracture of thyroid cartilage in $0.98 \%$, fracture of hyoid bone in $2.44 \%$ cases, tear of neck muscles in $91.22 \%$ cases and infiltration of blood in the soft tissues of neck in $99.51 \%$ cases and subcutaneous tissue was found contused in $22.44 \%$ cases and white glistening in $76.58 \%$ which differs from the study by Patel et $\mathrm{al}^{4}$ who found contusions in strap muscles of neck in $6.25 \%$ cases of hanging but no carotid artery tears or fractures of hyoid bone and thyroid cartilage. This study is partly consistent with the study by Patil et $\mathrm{al}^{6}$ where he found no victims of hyoid bone fracture. The results however varied from the studies of Sharma et $\mathrm{al}^{5}$ and Clement et al. ${ }^{8}$

In strangulation cases encountered cyanosis was found in $92.86 \%$ cases, discharge of semen was found in $2.86 \%$ cases, external injuries were found in $52.86 \%$ cases and froth from nostrils in $37.14 \%$ cases, tongue was protruded in $38.57 \%$ cases and it was clenched in between teeth in $21.43 \%$ cases. Rigor mortis present in $77.14 \%$ cases. These results closely correlate with the study made by Patel et $\mathrm{al}^{4}$ who observed the following; congestion in $100 \%$ cases, discharge of semen, urine and stools in zero percent cases, struggle marks in $100 \%$ cases.

Internal findings in strangulation cases observed were as follows- Contusions of strap muscles in $82.86 \%$ cases, fracture of thyroid cartilage in $11.43 \%$ cases, fracture of hyoid bone in $10 \%$ cases were observed. Intima of carotid artery was found torn in $60 \%$ cases while neck muscles were torn in $94.29 \%$ cases and infiltration of blood in the soft tissues was present in $100 \%$ cases. These results partially correlate with the study of Patel et $\mathrm{al}^{4}$ who observed strap muscle contusions in $100 \%$ cases and $66 \%$ cases having hyoid bone fracture with nil per fracture of thyroid cartilage. The results once again vary from the studies of Sharma et al, ${ }^{5}$ in which they found hyoid bone fracture in $21 \%$ cases, thyroid cartilage fracture in $17 \%$ cases and neck muscles were found torn in $54 \%$ cases and Clement et al, ${ }^{8}$ Patil et al ${ }^{6}$ in which they found hyoid bone fracture in $42 \%$ cases.

\section{Conclusion and Suggestions}

Ligature mark was situated above the level of the thyroid cartilage in most of the cases in hanging while it was either below or at the level of thyroid cartilage in strangulation. The preferred ligature material used in both hanging and strangulation cases was soft in most of the cases. As most of the postmortem cases of violent asphyxial deaths are being conducted by the doctors who are not Forensic experts and they found difficulty in concluding whether it is a case of hanging or strangulation. It is suggested that in the interest of justice to avoid confusion, in all cases of violent asphyxial deaths, the postmortem examination should be conducted by the Forensic experts only. Police personals should also be given training that they should not cut the ligature material and remove ligature material before postmortem examination so that easy differentiation of hanging and strangulation can be made. They should also routinely take the help of technology by video recording and photography of the scene of crime.

\section{Conflict of Interest: None}

\section{Source of Funding: Self}

Ethical Clearance: Taken from Thesis Research Committee.

\section{References}

1. Reddy KSN. The Essentials of Forensic Medicine and Toxicology. 28th ed. Hyderabad: Om Sai graphics. 2009; pp. 299-333.

2. Murkey PN, Ambedkar R, Tirpude BH, Khan S. Autopsy based study of cases of hanging with respect to marital status and place of hanging. Indian Journal of Forensic and Community Medicine, 2017;4(1):63-6

3. Subramanyam BV. Modi's Medical Jurisprudence and Toxicology. $22^{\text {nd }}$ ed. Death from asphyxia. Butter worth Ind. Pvt. Limited, New Delhi. 1999; pp. 252.

4. Patel AP, Bhoot RR, Patel DJ, Patel KA. Study of violent asphyxial death. International Journal of Medical Toxicology and Forensic Medicine. 
2013;3(2):48-57.

5. Sharma BR, Harish D, Sharma A, Sharma S, Singh H. Injuries to neck structures in deaths due to constriction of neck, with a special reference to hanging. Journal of Forensic and Legal Medicine. 2008;15(5):298-305.

6. Naik SK, Patil DY. Fracture of Hyoid Bone in cases of Asphyxial deaths resulting from constricting force round the neck. JIAFM. 2005;27(3):149-53.
7. Vijayanath V, Anitha MR, Shah RK, Babladi P, Reddy KS. Autopsy profile in cases of hanging. Journal of Forensic Medicine and Toxicology. 2009;26(1):34-6.

8. Clement R, Guay JP, Sauvageau A. Fracture of the neck structures in suicidal hangings: a retrospective study on contributing variables. Forensic Science International. 2011;207(1-3):122-6. 